\title{
Adrenocortical carcinoma: Pediatric aspects (Review)
}

\author{
FLORICA SANDRU $^{1,2}$, RĂZVAN-COSMIN PETCA ${ }^{3,4}$, MARA CARSOTE $^{5,6}$, AIDA PETCA $^{7,8}$, \\ MIHAI CRISTIAN DUMITRASCU ${ }^{7,9}$ and ADINA GHEMIGIAN ${ }^{5,6}$
}

\author{
${ }^{1}$ Department of Dermatology, 'Carol Davila University of Medicine and Pharmacy, 050474 Bucharest; \\ ${ }^{2}$ Department of Dermatology, 'Elias' Emergency Hospital, 011461 Bucharest; ${ }^{3}$ Department of Urology, \\ 'Carol Davila' University of Medicine and Pharmacy, 050474 Bucharest; ${ }^{4}$ Department of Urology, \\ 'Prof. Dr. Theodor Burghele' Clinical Hospital, 061344 Bucharest; ${ }^{5}$ Department of Endocrinology, \\ 'Carol Davila' University of Medicine and Pharmacy, 050474 Bucharest; ${ }^{6}$ Department of Endocrinology, \\ 'C.I. Parhon' National Institute of Endocrinology, 011863 Bucharest; ${ }^{7}$ Department of Obstetrics and Gynecology, \\ 'Carol Davila' University of Medicine and Pharmacy, 050474 Bucharest; ${ }^{8}$ Department of Obstetrics and Gynecology, \\ 'Elias' Emergency Hospital, 022461 Bucharest; ${ }^{9}$ Department of Obstetrics and Gynecology, \\ University Emergency Hospital, 050098 Bucharest, Romania
}

Received October 25, 2021; Accepted November 24, 2021

DOI: $10.3892 / \mathrm{etm} .2022 .11216$

\begin{abstract}
Adrenocortical carcinoma (adrenal cortex-derived cancer), an orphan malignancy, is a very aggressive disease that affects both adults and children with an annual incidence of 1-2 adult and $0.2-0.38$ pediatric cases/million (in the pediatric population it represents $0.2 \%$ of all cancers), with a female predominance. A total of $80-90 \%$ of cases have hormonal imbalances such as Cushing syndrome, virilization, and puberty anomalies. Precocious puberty (PP) of iso- or hetero-sexual pattern is independent of gonadotropin-releasing hormone (GnRH) (high testosterone/estrogens and low FSH/LH) but post-operative activation of GnRH may be expected (central $\mathrm{PP})$. PP is accompanied by accelerated growth while Cushing
\end{abstract}

Correspondence to: Dr Mihai Cristian Dumitrascu, Department of Obstetrics and Gynecology, 'Carol Davila' University of Medicine and Pharmacy, 169 Splaiul Independentei Street, 050474 Bucharest, Romania

E-mail: drdumitrascu@yahoo.com

Abbreviations: ALT, alternative lengthening of telomeres; ARMC5, Armadillo repeat containing 5; CD8-CTL, cytotoxic T lymphocytes; DHEAS, dehydroepiandrosterone; ENSAT, European Network for the Study of Adrenal Tumors; EGFR, epidermal growth factor receptor; EXPeRT, European Cooperative Study Group for Pediatric Rare Tumors; GWAS, genome-wide association studies; GnRH, gonadotropin-releasing hormone; IGF2, insulin-like growth factor 2; MEN1, multiple endocrine neoplasia type 1; mTOR, mechanistic target of rapamycin; MVD, microvessel density; NCDB, National Cancer Data Base; TP53, tumor protein p53; SNP, single nucleotide polymorphism; UPS, ubiquitin-proteasome system; VEGF, vascular endothelial growth factor

Key words: adrenocortical carcinoma, pediatric, adrenal tumor, cortisol, adrenal cortex, mitotane, adrenalectomy, Weiss score, Li-Fraumeni syndrome, virilization syndrome by reduced growth velocity. Pure androgen-secreting tumors have been exceptionally described. A total of $50-80 \%$ of children have different genetic/epigenetic anomalies involving tumor protein p53 (most often, almost half of the cases; with a population cluster in Southern Brazilian children), insulin-like growth factor, multiple endocrine neoplasia type 1 (MEN1), PRKAR1A, dysfunctional alternative lengthening of telomeres. Hereditary syndromes associated to adrenocortical carcinoma include Li-Fraumeni, Beckwith-Wiedemann, MEN1, and Lynch. Recently, mutations in epidermal growth factor receptor have been reported in teenagers, suggesting the future use of tyrosine kinase inhibitors. Adrenalectomy is the first line therapy offering the best prognosis if complete tumor removal is achieved; genetic testing is recommended before surgery. Adjuvant therapies are less standardized in children (mitotane is a key adjuvant drug in addition with different regimes of chemotherapy such as etoposide, Adriamycin and cisplatin). A Ki-67 value of at least $15 \%$ is a predictor of poor outcome. Weiss score also serves as a prognostic factor, as well as the tumor size at diagnosis. The prognosis of adrenocortical carcinoma is poor with an overall 5-year survival rate of 55\%; a Weiss score of at least 6 is associated with a 2-year survival rate of $35 \%$. At present, pediatric adrenocortical carcinoma still represents a severe condition that requires prompt intervention and a multidisciplinary team. Further development of molecular markers is required for an improved understanding of the disease thus improving the protocols of approach and the prognostic.

\section{Contents}

1. Introduction

2. Presentation

3. Associated genetic background

4. Management and prognosis

5. Future considerations

6. Conclusion 


\section{Introduction}

Adrenocortical carcinoma (adrenal cortex-derived cancer), an orphan malignancy, is a very aggressive disease that affects both adults and children with an annual incidence of 1-2 cases/million for adults vs. 0.2-0.38 cases/million in children, except for markedly higher rates in Southern Brazil due to high prevalence of tumor protein (TP53) p. R337H (R337H) mutation (1-3). It has a female predominance based on most studies (1-3). A strong genetic background for adrenocortical carcinoma in the pediatric population has been described $(1,2)$. A total of $50-80 \%$ of cases involve anomalies of genes such as TP53 (in half of the cases), formerly known as $\mathrm{p} 53$, insulin-like growth factor 2 (IGF2) overexpression, IGF1R, ZNRF3, CTNNB1, multiple endocrine neoplasia type 1 (MEN1), PRKAR1A, 11p15.5 (chromosome 11 anomalies) $(3,4)$. Recently, mutations in epidermal growth factor receptor (EGFR) have been reported in teenagers and young children diagnosed with adrenocortical carcinoma, indicating the potential future use of tyrosine kinase inhibitors in addition to traditional medication such as mitotane and chemotherapy regimens which are introduced at different stages during management, pre and post-tumor removal if surgery is feasible $(1,5)$. Adrenalectomy is the first line therapy offering the best prognosis, while the adjuvant therapies are less standardized in children; genetic testing is recommended before surgery and lifelong follow-up is required $(6,7)$. The tumor rapidly spreads at the local level and to distant sites $(6,8)$. In general, the pattern of this condition renders it a rather distinct entity than the same tumor identified in adults, despite the fact than even in pediatric cases the disease is extremely severe (for instance, in children the 5-year survival rate is 46-55\%) (9). In addition, the prognostic factors described in adults are not necessarily similar in children (10). Further markers of abnormal pathways in adrenal cancer such as IGF or mechanistic target of rapamycin (mTOR) are required for an improved therapeutic intervention (11). The aim of the present review was to focus on adrenocortical carcinoma based on a multi-disciplinary approach, particularly in the pediatric population. The present review represents an assessment of literature using PubMed database. Researched key words in different combinations included 'adrenocortical carcinoma', 'adrenal cancer', 'adrenal tumor', 'children' and 'pediatric'. A total of 70 references are cited (between 2009 and 2021) based on their clinical relevance. The level of statistical evidence varies from case reports, cases series to different types of studies. The majority of them are retrospective cohort/observational studies, population-based studies, certain are National Registry-based analyses, and also a meta-analysis that was published in 2021 was included.

\section{Presentation}

Adrenocortical carcinoma in children, representing $0.2 \%$ of all cancers in children, is considered rather a standalone condition when compared with adults with the same diagnosis $(12,13)$. A total of $80-90 \%$ of cases have an adrenal-related endocrine dysfunction (indicating that $10-20 \%$, or even $43 \%$ of the tumors, depending on the study, are non-functional) such as Cushing syndrome, virilization (single or associated with Cushing syndrome), or pubertal anomalies which are due to androgen with or without glucocorticoid excess (Fig. 1) (12-14). The incidentaloma scenario of detection is rarer than in adults (15). Precocious puberty (PP) of iso- or hetero-sexual pattern is independent of gonadotropin-releasing hormone $(\mathrm{GnRH})$ with high testosterone or estrogens (with consecutive low FSH and LH) but post-operative activation of GnRH may be expected with central (hypothalamic) PP (16-18). PP is accompanied by accelerated growth while Cushing syndrome by arrest growth $(19,20)$. Breast development may appear in both males and females $(19,21)$. Abnormally high levels of dehydroepiandrosterone (DHEAS) have also been reported (22). Pure androgen-secreting tumors underlying an adrenocortical carcinoma are exceptionally observed (23). Steroidogenic machinery may be provided by fetal adrenal tissue or even by Leydig cells as they have been revealed in isolated cases (24). As expected, hypercortisolemia of adrenal cause needs to be confirmed by specific tests (25). Another type of presentation is not related to endocrine features, but with the presence of a very large abdominal mass causing local pain and weight loss or associated metastases of the lung or liver $(26,27)$.

\section{Associated genetic background}

Genetic anomalies are more important in pediatric than adult cases of adrenocortical carcinoma and they ideally need to be evaluated before surgery (28). A potential involvement in adrenal cancer as well as certain types of renal cancer and meningioma have been described in association with ubiquitin-proteasome system (UPS) as a regulator of the Armadillo repeat containing (ARMC5) gene system (29). ARMC5 anomalies have also been described in bilateral adrenal hyperplasia of macronodular type associated with endocrine dysfunctions such as glucocorticoid with or without mineralocorticoid excess $(30,31)$. Adrenocortical carcinoma is part of a more complex tumorigenesis process in patients with Li-Fraumeni syndrome also introducing sarcomas of both bone and soft tissues, breast cancer at a young age, gastrointestinal cancers particularly of the colon and stomach, leukemia, and brain cancer $(32,33)$. The underlying mutation is TP53 (32). This is most frequently observed in the pediatric population confirmed with adrenocortical cancer (34). A retrospective single-centric study involving 23 patients admitted between 1977 and 2017 revealed a $50 \%$ prevalence of the mutation (10 out of 20 tested patients) on a cohort with a female/male ratio of 3.6:1 and a bimodal incidence (one peak incidence earlier in life between the age of 0 and 6 years and the other one after the age of 12 years) (34). TP53 R337H mutation is very frequent in Brazil where large population studies have been developed with a reported incidence of adrenocortical tumors of 4.8 in adults, and 6.4/million/year (depending on geographic area) in children younger than 10 years old (35). Another study including data from 19 population-based registries of Brazil revealed an incidence of adrenocortical cancer of 4 cases/million/year in individuals younger than 10 years old (36). In one study on TP53 R337H carriers, a higher count of cytotoxic T lymphocytes (CD8-CTL) was correlated with the diagnosis of adrenocortical cancer at very young age and stage I of the disease while the $\mathrm{Ki}-67$ value and Weiss score were not survival predictors (37). Adrenocortical carcinoma 


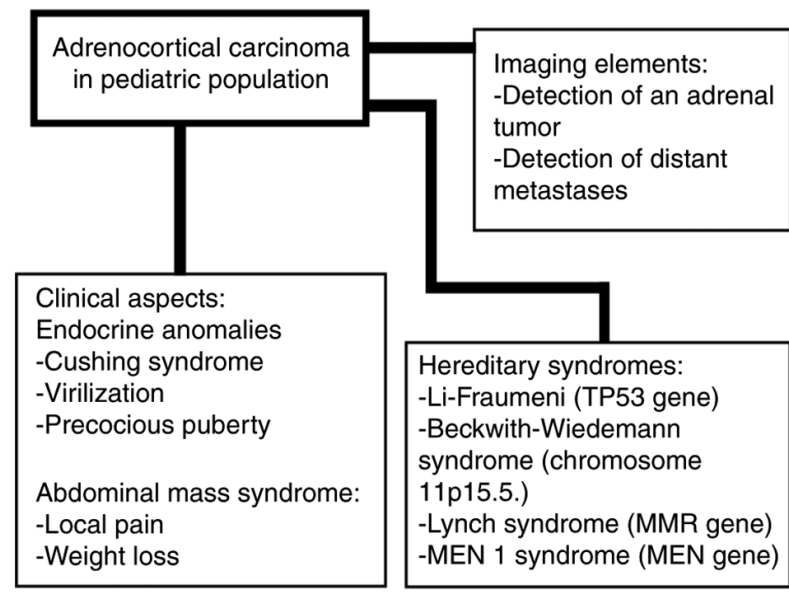

Figure 1. Brief presentation of adrenocortical carcinoma in children.

has an extremely low prevalence of $0.47-3.2 \%$ in subjects with Lynch syndrome. However, in other cancers, such as colorectal cancer and endometrial cancer, Lynch sundrome has a very high prevalence underlying the mutation of MMR (DNA mismatch repair) gene $(38,39)$. Due to poor prognosis and the importance of early recognition that offers an improved prognosis via adrenalectomy, screening of adrenocortical carcinoma in patients diagnosed with Lynch syndrome is recommended $(38,39)$.

In addition, alternative lengthening of telomeres (ALT) represents a potential dysfunctional mechanism in cancerous cells of adrenal cancer (40). Murine experiments revealed that besides the $\mathrm{p} 53 / \mathrm{Rb}$ pathway, the $\mathrm{Wnt} / \beta$-catenin signaling pathway may also be involved (41). Clinical studies on $\beta$-catenin $/ \mathrm{N}$-cadherin indicated the potential role of this pathway in tumorigenesis underlying adrenal cortex-derived carcinoma $(41,42)$. $\beta$-Catenin activity in association with CTNNB1 genes has been reported in relation to sclerosing bone dysplasia with adrenal tumors (43). A retrospective cohort study based on the German Childhood Cancer Registry, published in 2020, involving 321 subjects diagnosed with Beckwith-Wiedemann syndrome (which is associated with anomalies of chromosome 11p15.5.) revealed a 33-fold higher risk for different cancers such as hepatoblastoma, nephroblastoma but also, more rarely, adrenocortical carcinoma (44). In addition, the association of 11p15 or TP53 genes with abnormal activity of phosphodiesterases has been reported (45). Genome-wide association studies (GWAS) based on single nucleotide polymorphism (SNP) assays identified retinoic acid pathway anomalies in adrenocortical carcinoma (46). MEN type 1 syndrome caused by MEN1 gene mutation, which is associated with pituitary tumors or gastrointestinal and pancreatic neuroendocrine neoplasia has been reported to be present in adrenal tumors (47-49). However, pediatric adrenocortical carcinoma is rarer than adult adrenal cancer in MEN1 syndrome (50).

\section{Management and prognostic}

Weiss score, rather than I-IV staging according to the European Network for the Study of Adrenal Tumors (ENSAT) is essential for prognosis (51). A retrospective case series published in 2021 on 8 patients (male/female ratio of 2:6; median age of 6 years) revealed that survival for the next 2 years after diagnosis was $100 \%$ for stage II and $75 \%$ for stage IV (without achieving statistical significance), but in patients with a Weiss score $<6$ the 2-year survival rate was $100 \%$ which was statistically significantly higher when compared with the subjects with a Weiss score at least 6 or more who had a 2-year survival rate of $35 \%(\mathrm{P}=0.043)$; Weiss score being considered the most important prognostic factor (51). The combination of mitotane, etoposide, Adriamycin and cisplatin was revealed to be most useful in improving the prognosis (51). A comparative study from 2021, evaluated adults $(n=146)$ vs. children $<15$ years old $(n=44)$, and the results revealed: Female prevalence (more evident in adults: 84 vs. 61\%); adrenal Cushing syndrome more often observed in adults while virilization was more frequently identified in children (both clinical features with statistically significant differences between the two studied populations); and a $\mathrm{Ki}-67$ index of proliferation based on the immunohistochemistry report which was higher in children compared with adult correspondents, emerging as a useful prognostic marker, as well as the Weiss score (52). A Ki-67 value of least $15 \%$ represents a powerful predictor of poor outcome in the pediatric population (52). Ki-67 is an independent prognostic factor in adults as well (53). An extensive German study suggested the following Ki-67 cut-offs: $<10 \%, 10-19 \%$, and $\geq 20 \%$ (54). Another study revealed that a Ki-67 cut-off value of $10 \%$ was useful for prediction (55). Variations between manual/digital assessments of Ki-67 have been reported (with digital assessment superior to manual analysis which displays less reproducible values) (56). Surgical removal of the tumor, if feasible, remains the first line of therapy; procedures of approach vary, but successful tumor removal represents a major predictor of favorable outcome $(57,58)$. Metastases removal may be useful in addition to mitotane, although chemotherapy regimens in children are less clear when compared to adults (59). A retrospective study from 2021 on 24 children with adrenal tumors (median age at diagnosis, 78 months; confirmed adrenocortical carcinoma in 14 cases) reported the use of a transabdominal approach (in combination with chemotherapy in certain cases), but also an additional thoraco-abdominal approach which was applied if the tumor had spread to the lungs or the primary adrenal tumor was extensive (57). A complex meta-analysis published in 2021 based on 42 studies between 1994 and 2020 (including a total of 1,006 children aged $<18$ years) highlighted the following factors of favorable outcome with statistical significance: Age at diagnosis $<4$ years old, complete tumor surgical removal, decreased tumor volume, size, and weight, adrenal cancer without hormonal burden (the presence of adrenal Cushing syndrome was an indicator of poor prognosis) and stage I disease (60). A previous study revealed that virilization was a favorable prognostic factor (12). In addition, the control of tumor-related Cushing syndrome may be achieved not only through mitotane, but also by using other adrenal blockers that are mostly used in adults, and only exceptionally used in children to date (61). In 2020, a case of a 2-month-old female treated with etomidate $(0.03 \mathrm{mg} / \mathrm{hg} / \mathrm{h})$ to control high cortisol levels was published, and further implementation of the mentioned drug in complex regimes is required (61). Mitotane, an adrenolytic chemotherapeutic, causes adrenal insufficiency 
which requires glucocorticoid and mineralocorticoid substitution, increased liver enzymes, high cholesterol, gynecomastia, and primary hypothyroidism in adults and children (62). An estrogen-like effect was suggested as a possible cause of PP (62). An analysis from Mayo Clinic between 1950 and 2017 included 41 subjects with adrenal cortex carcinoma having an onset before the age of 21 years (63). The study revealed: A median age at diagnosis of 15.7 years; $54 \%$ of children had at least one hormonal dysfunction; metastases were more often identified in children older than 12 years (particularly at the hepatic and pulmonary level); the 2-year survival rate was $61 \%$, while the 5-year survival rate was $46 \%$ (63). Metastases represent an independent factor of poor outcome (63). The European Cooperative Study Group for Pediatric Rare Tumors (EXPeRT) revealed in a multi-centric-based European study that included individuals younger than 18 years diagnosed with adrenocortical carcinoma $(n=82)$ that the 3 -year progression-free survival rate was $51 \%$, while the overall survival rate was 55\% (64). Poor prognostic factors were: Vascular invasion and incomplete surgery, co-presence of metastases; large tumor volume if the disease was localized (64). The 'Helsinki score', a model of prediction for metastases in adrenocortical carcinomas, combines pathological data and immunohistochemistry data (Ki-67) (65). A previous study on 255 adrenal cortex carcinomas confirmed a good equivalence of the Helsinki score with the Weiss score and a good predictive value (65). A retrospective, observational study based on the Brazilian National Institute of Cancer, between 1997 and 2015 included 27 pediatric (median age, 3.6 years) adrenocortical carcinomas with a median carcinoma diameter of $8.2 \mathrm{~cm}$ (66). The most frequent medical drug that was used as adjuvant medication was mitotane (66). Poor prognostic factors included increased tumor size, a high Weiss score, incomplete surgery, and histological data revealing capsular invasion (66). The National Cancer Data Base (NCDB)-related study on 111 subjects (18 years or younger) confirmed with adrenocortical cancer (between 1998 and 2011) revealed a median age at diagnosis of 4 years ( $48 \%$ of the patients were younger than 3 years old); female sex predominance (69\%); a median diameter of $9.5 \mathrm{~cm}$; and 1- and 3-year survival rates of 70 and $64 \%$, respectively (67). Survival depended on the initial tumor size, associated metastases, local spreading of the disease and the success of the surgical procedure as reflected by the margin status (67). Another pediatric study on 27 cases revealed an increased expression of endoglin MVD (intra-tumoral microvessel density) and a low expression of CD34 MVD as poor prognostic factors while vascular endothelial growth factor (VEGF) was not relevant (68). The routine use of growth factors as prognostic factors is currently under evaluation.

\section{Future considerations}

Multiple aspects of adrenocortical carcinoma remain poorly understood. Another clinical association, probably less relevant in every day practice, is the co-presence of pulmonary arteriovenous malformation (based on a case report with statistical evidence), however, the current level of statistical evidence is low (69). Uncommon predictors of poor outcome such as Fetal and Adult Testis-Expressed 1 (FATE1) expression have been revealed in adults, not in children and further studies are necessary (70).

\section{Conclusions}

At present, pediatric adrenocortical carcinoma still represents a severe condition that requires prompt intervention and a multidisciplinary team. Further development of molecular markers is required for a deeper understanding of the disease thus improving the protocols of approach and the prognosis.

\section{Acknowledgements}

Not applicable.

\section{Funding}

Not applicable.

\section{Availability of data and materials}

Not applicable.

\section{Authors' contributions}

FS drafted the manuscript and critically revised the final version. RCP researched the literature. MC drafted the manuscript, researched the bibliography, and created the figure. AP approved the final version and refined the references. MCD wrote the manuscript and is the corresponding author and AG critically revised the final version. All authors read and approved the final manuscript. Data authentication is not applicable.

\section{Ethics approval and consent to participate}

Not applicable.

\section{Patient consent for publication}

Not applicable.

\section{Competing interests}

The authors declare that they have no competing interests.

\section{References}

1. Akhavanfard S, Yehia L, Padmanabhan R, Reynolds JP, Ni Y and Eng C: Germline EGFR variants are over-represented in adolescents and young adults (AYA) with adrenocortical carcinoma. Hum Mol Genet 29: 3679-3690, 2021.

2. Jarzembowski JA: New prognostic indicators in pediatric adrenal tumors: Neuroblastoma and adrenal cortical tumors, can we predict when these will behave badly? Surg Pathol Clin 13: 625-641, 2020.

3. Kamilaris CDC, Hannah-Shmouni F and Stratakis CA: Adrenocortical tumorigenesis: Lessons from genetics. Best Pract Res Clin Endocrinol Metab 34: 101428, 2020.

4. Ribeiro TC, Jorge AA, Almeida MQ, Mariani BM, Nishi MY, Mendonca BB, Fragoso MC and Latronico AC: Amplification of the insulin-like growth factor 1 receptor gene is a rare event in adrenocortical adenocarcinomas: Searching for potential mechanisms of overexpression. Biomed Res Int 2014: 936031, 2014. 
5. Traynor MD Jr, Sada A, Thompson GB, Moir CR, Bancos I, Farley DR, Dy BM, Lyden ML, Habermann EB and McKenzie TJ: Adrenalectomy for non-neuroblastic pathology in children. Pediatr Surg Int 36: 129-135, 2020.

6. Brondani VB and Fragoso MCBV: Pediatric adrenocortical tumor-review and management update. Curr Opin Endocrinol Diabetes Obes 27: 177-186, 2020.

7. Zekri W, Hammad M, Rashed WM, Ahmed G, Elshafie M, Adly MH, Elborai Y, Abdalla B, Taha H, Elkinaae N, et al: The outcome of childhood adrenocortical carcinoma in Egypt: A model from developing countries. Pediatr Hematol Oncol 37: 198-210, 2020

8. Longui CA: Adrenal cortical carcinoma in infancy. Rev Paul Pediatr 37: 2-3, 2019.

9. Breidbart E, Cameo T, Garvin JH, Hibshoosh $\mathrm{H}$ and Oberfield SE: Pubertal outcome in a female with virilizing adrenocortical carcinoma. J Pediatr Endocrinol Metab 29: 503-509, 2016.

10. Erickson LA: Challenges in surgical pathology of adrenocortical tumours. Histopathology 72: 82-96, 2018.

11. De Martino MC, van Koetsveld PM, Feelders RA, de Herder WW, Dogan F, Janssen JAMJL, Hofste Op Bruinink D, Pivonello C, Waaijers AM, Colao A, et al: IGF and mTOR pathway expression and in vitro effects of linsitinib and mTOR inhibitors in adrenocortical cancer. Endocrine 64: 673-684, 2019.

12. Pinto EM, Zambetti GP and Rodriguez-Galindo C: Pediatric adrenocortical tumours. Best Pract Res Clin Endocrinol Metab 34: 101448, 2020.

13. Kastenberg ZJ and Scaife ER: Adrenocortical tumors in children. Semin Pediatr Surg 29: 150927, 2020.

14. Sipayya V, Yadav YK, Arora R, Sharma U and Gupta K: Virilizing adrenocortical carcinoma in a child: A rare enigma. Indian J Endocrinol Metab 16: 621-623, 2012.

15. Khan MS, Ali A, Tariq I, Khan MA, Bakar MA and Anwar AW: A clinical study and treatment results of adrenocortical carcinoma patients presented in Shaukat Khanum Memorial cancer hospital and research center, Lahore. J Pak Med Assoc 69: 717-719, 2019.

16. Goyal A, Malhotra R and Khadgawat R: Precocious pseudopuberty due to virilising adrenocortical carcinoma progressing to central precocious puberty after surgery. BMJ Case Rep 12: e229476, 2019

17. Shimelis D, Tadesse A, Schneider J and Tilahun B: Adrenocortical carcinoma in a $3 \%$ years old girl with hetro-sexual precocity. Ethiop Med J 52: 91-94, 2014.

18. Miyoshi Y, Oue T, Oowari M, Soh H, Tachibana M, Kimura S, Kiyohara Y, Yamada H, Bessyo K, Mushiake S, et al: A case of pediatric virilizing adrenocortical tumor resulting in hypothalamic-pituitary activation and central precocious puberty following surgical removal. Endocr J 56: 975-982, 2009.

19. Takeuchi T, Yoto Y, Ishii A, Tsugawa T, Yamamoto M, Hori T, Kamasaki H, Nogami K, Oda T, Nui A, et al: Adrenocortical carcinoma characterized by gynecomastia: A case report. Clin Pediatr Endocrinol 27: 9-18, 2018.

20. Ghazizadeh F, Ebadi M, Alavi S, Arzanian M, Shamsian B and Jadali F: Adrenocortical carcinoma presenting with heterosexual pseudoprecocious puberty shortly after birth: Case report and review. Ecancermedicalscience 7: 289, 2013.

21. Wendt S, Shelso J, Wright K and Furman W: Neoplastic causes of abnormal puberty. Pediatr Blood Cancer 61: 664-671, 2014.

22. Idkowiak J, Elhassan YS, Mannion P, Smith K, Webster R, Saraff V, Barrett TG, Shaw NJ, Krone N, Dias RP, et al: Causes, patterns and severity of androgen excess in 487 consecutively recruited pre- and post-pubertal children. Eur J Endocrinol 180: 213-221, 2019

23. Tong A, Jiang J, Wang F, Li C, Zhang Y and Wu X: Pure androgen-producing adrenal tumor: Clinical features and pathogenesis. Endocr Pract 23: 399-407, 2017.

24. Fujisawa Y, Sakaguchi K, Ono H, Yamaguchi R, Kato F, Kagami M, Fukami M and Ogata T: Combined steroidogenic characters of fetal adrenal and Leydig cells in childhood adrenocortical carcinoma. J Steroid Biochem Mol Biol 159: 86-93, 2016

25. Chen QL, Su Z, Li YH, Ma HM, Chen HS and Du ML: Clinical characteristics of adrenocortical tumors in children. J Pediatr Endocrinol Metab 24: 535-541, 2011.

26. Jaruratanasirikul S, Patarapinyokul S and Mitranun W: Androgen-producing adrenocortical carcinoma: Report of 3 cases with different clinical presentations. J Med Assoc Thai 95: 816-20, 2012.

27. Mittal A, Aggarwal M and Debata P: Large adrenocortical carcinoma presenting as an adenoma with precocious puberty. Indian J Pediatr 79: 820-821, 2012.
28. Pinto EM, Chen X, Easton J, Finkelstein D, Liu Z, Pounds S, Rodriguez-Galindo C, Lund TC, Mardis ER, Wilson RK, et al: Genomic landscape of paediatric adrenocortical tumours. Nat Commun 6: 6302, 2015.

29. Yan G, Liu N, Tian J, Fu Y, Wei W, Zou J, Li S, Wang Q, Li K and Wang J: Deubiquitylation and stabilization of ARMC5 by ubiquitin-specific processing protease 7 (USP7) are critical for RCC proliferation. J Cell Mol Med 25: 3149-3159, 2021

30. Espiard S and Bertherat J: The genetics of adrenocortical tumors. Endocrinol Metab Clin North Am 44: 311-334, 2015.

31. Jouinot A, Armignacco R and Assié G: Genomics of benign adrenocortical tumors. J Steroid Biochem Mol Biol 193: 105414, 2019.

32. Daly MB, Pal T, Berry MP, Buys SS, Dickson P, Domchek SM, Elkhanany A, Friedman S, Goggins M, Hutton ML, et al: Genetic/familial high-risk assessment: Breast, ovarian, and pancreatic, version 2.2021, NCCN clinical practice guidelines in oncology. J Natl Compr Canc Netw 19: 77-102, 2021.

33. Ferreira AM, Brondani VB, Helena VP, Charchar HLS, Zerbini MCN, Leite LAS, Hoff AO, Latronico AC, Mendonca BB, Diz MDPE, et al: Clinical spectrum of $\mathrm{Li}$-Fraumeni syndrome/Li-Fraumeni-like syndrome in Brazilian individuals with the TP53 p.R337H mutation. J Steroid Biochem Mol Biol 190: 250-255, 2019.

34. Brenna CTA, Michaeli O, Wasserman JD and Malkin D: Clinical outcomes of children with adrenocortical carcinoma in the context of germline TP53 status. J Pediatr Hematol Oncol 43: e635-e641, 2021

35. Costa TEJ, Gerber VKQ, Ibañez HC, Melanda VS, Parise IZS, Watanabe FM, Pianovski MAD, Fiori CMCM, Fabro ALMR, Silva DBD, et al: Penetrance of the TP53 R337H mutation and pediatric adrenocortical carcinoma incidence associated with environmental influences in a 12-year observational cohort in Southern Brazil. Cancers (Basel) 11: 1804, 2019.

36. Kostiainen I, Hakaste L, Kejo P, Parviainen H, Laine T, Löyttyniemi E, Pennanen M, Arola J, Haglund C, Heiskanen I and Schalin-Jäntti C: Adrenocortical carcinoma: Presentation and outcome of a contemporary patient series. Endocrine 65: 166-174, 2019.

37. Parise IZS, Parise GA, Noronha L, Surakhy M, Woiski TD, Silva DB, Costa TEB, Del-Valle MHCP, Komechen H, Rosati R, et al: The prognostic role of $\mathrm{CD}^{+} \mathrm{T}$ lymphocytes in childhood adrenocortical carcinomas compared to Ki-67, PD-1, PD-L1, and the weiss score. Cancers (Basel) 11: 1730, 2019.

38. Raymond VM, Everett JN, Furtado LV, Gustafson SL, Jungbluth CR, Gruber SB, Hammer GD, Stoffel EM, Greenson JK, Giordano TJ and Else T: Adrenocortical carcinoma is a lynch syndrome-associated cancer. J Clin Oncol 31: 3012-3018, 2013.

39. Domènech M, Grau E, Solanes A, Izquierdo A, Del Valle J, Carrato C, Pineda M, Dueñas N, Pujol M, Lázaro C, et al: characteristics of adrenocortical carcinoma associated with lynch syndrome. J Clin Endocrinol Metab 106: 318-325, 2021.

40. Sung JY, Lim HW, Joung JG and Park WY: Pan-cancer analysis of alternative lengthening of telomere activity. Cancers (Basel) 12: 2207, 2020.

41. Borges KS, Pignatti E, Leng S, Kariyawasam D, Ruiz-Babot G, Ramalho FS, Taketo MM, Carlone DL and Breault DT: Wnt/ $\beta$-catenin activation cooperates with loss of p53 to cause adrenocortical carcinoma in mice. Oncogene 39: 5282-5291, 2020.

42. Rubin B, Regazzo D, Redaelli M, Mucignat C, Citton M, Iacobone M, Scaroni C, Betterle C, Mantero F, Fassina A, et al: Investigation of $\mathrm{N}$-cadherin/ $\beta$-catenin expression in adrenocortical tumors. Tumour Biol 37: 13545-13555, 2016.

43. Peng H, Jenkins ZA, White R, Connors S, Hunter MF, Ronan A, Zankl A, Markie DM, Daniel PB and Robertson SP: An activating variant in CTNNB1 is associated with a sclerosing bone dysplasia and adrenocortical neoplasia. J Clin Endocrinol Metab 105: dgaa034, 2020

44. Cöktü S, Spix C, Kaiser M, Beygo J, Kleinle S, Bachmann N, Kohlschmidt N, Prawitt D, Beckmann A, Klaes R, et al: Cancer incidence and spectrum among children with genetically confirmed Beckwith-Wiedemann spectrum in Germany: A retrospective cohort study. Br J Cancer 123: 619-623, 2020.

45. Pinto EM, Faucz FR, Paza LZ, Wu G, Fernandes ES, Bertherat J, Stratakis CA, Lalli E, Ribeiro RC, Rodriguez-Galindo C, et al: Germline variants in phosphodiesterase genes and genetic predisposition to pediatric adrenocortical tumors. Cancers (Basel) 12: 506, 2020 
46. Surakhy M, Wallace M, Bond E, Grochola LF, Perez H, Di Giovannantonio M, Zhang P, Malkin D, Carter $H$, Parise IZS, et al: A common polymorphism in the retinoic acid pathway modifies adrenocortical carcinoma age-dependent incidence. Br J Cancer 122: 1231-1241, 2020.

47. Harada K, Yasuda M, Hasegawa K, Yamazaki Y, Sasano H and Otsuka F: A novel case of myxoid variant of adrenocortical carcinoma in a patient with multiple endocrine neoplasia type 1. Endocr J 66: 739-744, 2019.

48. Wang W, Han R, Ye L, Xie J, Tao B, Sun F, Zhuo R, Chen X, Deng X, Ye C, et al: Adrenocortical carcinoma in patients with MEN1: A kindred report and review of the literature. Endocr Connect 8: 230-238, 2019.

49. Al-Salameh A, Cadiot G, Calender A, Goudet P and Chanson P: Clinical aspects of multiple endocrine neoplasia type 1 . Nat Rev Endocrinol 17: 207-224, 2021.

50. Else T and Rodriguez-Galindo C: 5th International ACC Symposium: Hereditary predisposition to childhood ACC and the associated molecular phenotype: 5th International ACC symposium session: Not just for kids! Horm Cancer 7: 36-39, 2016.

51. Li J, Zhang W, Hu H, Zhang Y, Wen Y and Huang D: Adrenocortical carcinoma in eight children: A report and literature review. Cancer Manag Res 13: 1307-1314, 2021

52. Martins-Filho SN, Almeida MQ, Soares I, Wakamatsu A, Alves VAF, Fragoso MCBV and Zerbini MCN: Clinical impact of pathological features including the Ki-67 labeling index on diagnosis and prognosis of adult and pediatric adrenocortical tumors. Endocr Pathol 32: 288-300, 2021.

53. Zhang F, Zhang F, Liu Z, Wu K, Zhu Y and Lu Y: Prognostic role of $\mathrm{Ki}-67$ in adrenocortical carcinoma after primary resection: A retrospective mono-institutional study. Adv Ther 36: 2756-2768, 2019.

54. Beuschlein F, Weigel J, Saeger W, Kroiss M, Wild V, Daffara F, Libé R, Ardito A, Al Ghuzlan A, Quinkler M, et al: Major prognostic role of Ki67 in localized adrenocortical carcinoma after complete resection. J Clin Endocrinol Metab 100: 841-849, 2015.

55. Yamazaki Y, Nakamura Y, Shibahara Y, Konosu-Fukaya S, Sato N, Kubota-Nakayama F, Oki Y, Baba S, Midorikawa S, Morimoto R, et al: Comparison of the methods for measuring the Ki-67 labeling index in adrenocortical carcinoma: Manual versus digital image analysis. Hum Pathol 53: 41-50, 2016.

56. Papathomas TG, Pucci E, Giordano TJ, Lu H, Duregon E, Volante M, Papotti M, Lloyd RV, Tischler AS, van Nederveen $\mathrm{FH}$, et al: An international Ki67 reproducibility study in adrenal cortical carcinoma. Am J Surg Pathol 40: 569-576, 2016.

57. Ardicli B, User IR, Ciftci AO, Akyuz C, Kutluk MT, Yalcin B, Gonc N, Ozon ZA, Alikasifoglu A, Oguz B, et al: Adrenocortical tumours in children: A review of surgical management at a tertiary care centre. ANZ J Surg 91: 992-999, 2021.

58. Orbach L, Nachmany I, Goykhman Y, Lahat G, Yossepowitch O, Beri A, Ben-Gal Y, Klausner JM and Lubezky N: Surgical approach to abdominal tumors involving the inferior vena cava. Isr Med Assoc J 22: 364-368, 2020.
59. Mirsharifi A, Vasei M, Sadeghian E, Ghorbani-Abdehgah A and Naybandi Atashi S: Extra-adrenal, non-functional adrenocortical carcinoma presenting with acute abdomen: A case report. J Med Case Rep 14: 107, 2020.

60. Zambaiti E, Duci M, De Corti F, Gamba P, Dall'Igna P, Ghidini F and Virgone C: Clinical prognostic factors in pediatric adrenocortical tumors: A meta-analysis. Pediatr Blood Cancer 68: e28836, 2021.

61. Kwon A, Choi Y, Jung JW, Suh J and Kim HS: Using etomidate in a 2-month-old infant with cushing syndrome due to adrenocortical carcinoma. J Clin Res Pediatr Endocrinol 2020 (Epub ahead of print).

62. Oddie PD, Albert BB, Hofman PL, Jefferies C, Laughton S and Carter PJ: Mitotane in the treatment of childhood adrenocortical carcinoma: A potent endocrine disruptor. Endocrinol Diabetes Metab Case Rep 2018: 18-0059, 2018

63. Gupta N, Rivera M, Novotny P, Rodriguez V, Bancos I and Lteif A: Adrenocortical carcinoma in children: A clinicopathological analysis of 41 patients at the mayo clinic from 1950 to 2017. Horm Res Paediatr 90: 8-18, 2018.

64. Cecchetto G, Ganarin A, Bien E, Vorwerk P, Bisogno G, Godzinski J, Dall'Igna P, Reguerre Y, Schneider D, Brugières L, et al: Outcome and prognostic factors in high-risk childhood adrenocortical carcinomas: A report from the European Cooperative Study Group on Pediatric Rare Tumors (EXPeRT). Pediatr Blood Cancer 64: 2017.

65. Duregon E, Cappellesso R, Maffeis V, Zaggia B, Ventura L, Berruti A, Terzolo M, Fassina A, Volante M and Papotti M: Validation of the prognostic role of the 'Helsinki Score' in 225 cases of adrenocortical carcinoma. Hum Pathol 62: 1-7, 2017.

66. Bulzico D, de Faria PA, de Paula MP, Bordallo MA, Pessoa CH, Corbo R, Ferman S, Vaisman M and Neto LV: Recurrence and mortality prognostic factors in childhood adrenocortical tumors: Analysis from the Brazilian National Institute of Cancer experience. Pediatr Hematol Oncol 33: 248-258, 2016.

67. Gulack BC, Rialon KL, Englum BR, Kim J, Talbot LJ, Adibe OO, Rice HE and Tracy ET: Factors associated with survival in pediatric adrenocortical carcinoma: An analysis of the National cancer data base (NCDB). J Pediatr Surg 51: 172-177, 2016.

68. Dias AI, Fachin CG, Avó LR, Frazão CV, Caran EM, Schettini ST, Alves MT, Ribeiro RC and Abib Sde C: Correlation between selected angiogenic markers and prognosis in pediatric adrenocortical tumors: Angiogenic markers and prognosis in pediatric ACTs. J Pediatr Surg 50: 1323-1328, 2015.

69. Rahat-Ul-Ain: Acquired pulmonary arteriovenous malformation in a case of a pediatric adrenocortical carcinoma. J Coll Physicians Surg Pak 31: 119-120, 2021.

70. Doghman-Bouguerra M, Finetti P, Durand N, Parise IZS Sbiera S, Cantini G, Canu L, Hescot S, Figueiredo MMO, Komechen $\mathrm{H}$, et al: Cancer-testis antigen fatel expression in adrenocortical tumors is associated with a pervasive autoimmune response and is a marker of malignancy in adult, but not children, ACC. Cancers (Basel) 12: 689, 2020. 